\title{
Food Groups that Exacerbate Sinusitis among Saudi Patients
}

\author{
Manal Abdulaziz Murad', Hoda Jehad Abousada2*, Ghaida Abdullah Aldugman³ ${ }^{3}$ Nesreen Nabeel Qusti ${ }^{4}$, \\ Shahad Daifalla Alsulaimani ${ }^{5}$, Sahira Jilan Al Nahari ${ }^{6}$, Mona Ibrahim Alnaimi ${ }^{6}$, Aouss Khalid Alsarsh
}

\author{
'Department of Family Medicine, Faculty of Medicine, King Abdulaziz University, Jeddah, Saudi Arabia. \\ 2Obstetrics and Gynecology Physician, King Fahad Armed Forces Hospital, Jeddah, Saudi Arabia. \\ 'Faculty of Medicine, Najran University, Najran, Saudi Arabia. \\ 4Family Medicine Resident, JPFCM (Joint Program Family and Community Medicine), King Abdulaziz University, Jeddah, Saudi Arabia. \\ 'Batterjee Medical College, Jeddah, Saudi Arabia. \\ ${ }^{6}$ Faculty of Medicine, King Abdulaziz University, Jeddah, Saudi Arabia. \\ 'Armed Forces Hospital, South Region, Saudi Arabia. \\ *Correspondence to: Hoda Jehad Abousada (E-mail: dr.huda1992@outlook.com) \\ (Submitted: 13 March 2021 - Revised version received: 04 April 2021 - Accepted: 29 April 2021 - Published online: 26 August 2021)
}

\begin{abstract}
Objective This study aimed to identify associations between specific food categories and aggravation of symptoms of chronic rhinosinusitis.

Methods This was a prospective, cross-sectional questionnaire study. Patients provided details about the categories of food that they consumed, as well as symptoms related to sinusitis. The data was extracted onto a spreadsheet and analysed using chi-square testing.

Results A small percentage of patients (4\%) associated food categories with exacerbations of sinus symptoms. Chocolate was the most common trigger, followed by white flour foods. Several patients (33\%) were not aware of the association between food and sinus symptoms. Conclusion Some food categories can exacerbate sinusitis in a specific population subset. Patients should be encouraged to maintain a food diary so that they can identify relevant triggers and these can be avoided in the future.

Keywords Rhinosinusitis, cross-sectional study, food allergy, histamine, chocolate, white flour
\end{abstract}

\section{Introduction}

Rhinosinusitis is an extremely common health complaint, and affects up to $14.7 \%$ of the population in the United States each year. Although this condition is not associated with extreme morbidity or mortality, it is nevertheless responsible for a decrease in the quality of life and loss of productivity. The direct healthcare costs owing to this condition are estimated to be $\$ 2.4$ million each year, excluding the cost of radiographic imaging and surgery.

Acute rhinosinusitis is usually of viral origin, and the disease is self-limiting. On the other hand, chronic rhinosinusitis is extremely difficult to manage, and its etiology remains obscure. While it was earlier suggested that pathogens play a role in the emergence of chronic rhinosinusitis, experts now concur that this condition occurs due to an imbalance between the host, micro-organisms and other exogenous factors such as allergens. ${ }^{2}$

Recent studies have attributed greater importance to the role of food allergens in the development of chronic sinusitis. Food allergens are already known risk factors for lower respiratory tract conditions such as asthma. ${ }^{3}$ Few studies have also established that patients with chronic rhinosinusitis are more likely to have food allergies as compared to controls. ${ }^{4,5}$ Moreover, food allergens and aeroallergens have been shown to have cross-reactivity. ${ }^{6}$

In this context, it would be helpful to document specific foods that are known to trigger episodes if rhinosinutitis in the adult population. Although several anecdotal reports are available pertaining to foods that must be avoided in chronic sinusitis, quantitative scientific evidence on this subject is lacking. Therefore, the aim of the current study was to identify specific categories of foods that could trigger exacerbations of rhinosinusitis.

\section{Patients and Methods}

The current study was a cross-sectional, questionnaire study. This study was conducted in accordance with the STROBE guidelines for cross-sectional studies, ${ }^{7}$ and ethical approval was obtained from the Institutional Review Board prior to beginning the study.

The source of samples for the study included patients who attended the outpatient Department of Family Medicine at King Abdulaziz University in the Kingdom of Saudi Arabia. Patients aged between 18 to 80 years, who were diagnosed with chronic rhinosinusitis were included in the study. Patients outside this age group, and who did not receive a definite diagnosis of chronic rhinosinusitis were excluded. Patients who already had documented food allergies were also excluded.

A written informed consent was obtained from all patients who met the inclusion criteria and consented to be a part of the study. These patients were asked to complete a questionnaire. Apart from demographic details, the questionnaire collected information pertaining to five specific food groups processed foods, high-calorie foods, fried foods, fatty meats, and foods high in sugar. Participants were questioned on the development of symptoms of sinusitis in relation to these food groups.

Information from the questionnaire study was collected and extracted onto a digital spreadsheet. Descriptive analysis of all the data was performed. The frequency of symptoms between the different food groups was assessed using the chi square test or Mc Nemar's exact test. All data analysis was carried out using SPSS version 22. 


\section{Results}

A total of 630 patients were recruited for the study. Of these, 481 patients were female $(76.35 \%)$ and 149 patients were male (23.65\%). The age of all the patients ranged from 18 to 77 years, with a mean age of 30.48 years. While all patients had been suffering from chronic rhinosinusitis, the duration of the current episode varied. At least $65.14 \%$ of all patients had been experiencing exacerbations for $2-8$ weeks, and $43.6 \%$ of the patients had experienced exacerbations for longer than 12 weeks. Only $13 \%$ of the patients reported that the current episode lasted for 4 to 8 weeks.

Six categories of foods were studied as potential sinus irritants. On an average, $4 \%$ of patients associated sinus exacerbations with different categories of foods. The highest food irritant appeared to be chocolate, which triggered sinus symptoms in $7.6 \%$ of all patients; followed by white flour foods, which triggered symptoms in $6.3 \%$ of all patients. The food that was least associated with sinus symptoms was mashed potatoes, which only exacerbated symptoms in $1.7 \%$ of all patients. The frequency of sinusitis exacerbations with different food groups is outlined in Table 1 .

We performed cross-comparisons of each of these food categories with each other. This is outlined in Table 2. In the cross-comparisons, it was noted that the frequency of sinus symptom exacerbation with mashed potatoes was significantly less as compared to the other food groups. The frequency of symptom exacerbation was significantly higher with chocolate as compared to pastries, fatty meats, white sugar and fried foods. A significantly high increase in symptom frequency was also observed when white flour foods were consumed, as compared to white sugars. None of the other comparisons showed significant differences.

One important finding that emerged from this questionnaire study was the lack of awareness that many patients had in correlating dietary foods to their sinusitis symptoms. Between $27 \%$ to $33 \%$ of all patients were not able to provide information on whether or not different foods triggered sinus symptoms.

\section{Discussion}

This cross-sectional questionnaire study attempted to identify specific food groups that could trigger symptoms of sinusitis in patients with already established rhinosinusitis. Overall, it was revealed that only a small percentage of symptom

\begin{tabular}{lcc}
\hline $\begin{array}{l}\text { Table 1. Frequency of rhinosinusitis symptoms on consumption } \\
\text { of different food groups }\end{array}$ \\
\hline Food category & $\begin{array}{c}\text { No. of patients with } \\
\text { sinus symptom } \\
\text { exacerbation }\end{array}$ & Percentage \\
\hline Fried foods & 27 & 4.9 \\
White sugar & 20 & 3.7 \\
White flour & 34 & 6.3 \\
Fatty meats & 23 & 4.2 \\
Mashed potatoes & 9 & 1.7 \\
Pastries & 24 & 4.4 \\
Chocolate & 41 & 7.6 \\
\hline
\end{tabular}

exacerbations are associated with consumption of specific food groups. Nevertheless, these findings could play a key role in managing those patients in whom there are obvious food triggers.

Several alternative medicine streams believe that diet that a patient consumes is strongly related to exacerbation of chronic rhinosinusitis. Some of the foods that alternative experts recommend avoiding include dairy products, sugars, caffeine and refined foods. It has been suggested that specific food categories, such as dairy products, wheat and corn, can lead to formation of 'globular' mucus rather than 'planar' mucus that may be difficult to drain. ${ }^{8}$

While allopathic medicine has not moved completely in this direction, there are a few studies that have been conducted in relation to diet and chronic rhinosinusitis.

There are a few studies in literature that have evaluated the effect of diet on related conditions. Calatayud et al. assessed the effect of the Mediterranean diet on children who had recurrent colds and frequent inflammatory complications. ${ }^{9}$ The Mediterranean diet encourages the consumption of fresh fruits, vegetables and whole grains, as well as fish and healthy fats. Dairy consumption is suggested in moderation and meat consumption is limited. When this diet was followed by 128 children in the study, the authors noted decrease in the intensity and number of catarrhal episodes, as well as a decrease in antibiotic use and hospital visits. The influence of diet in childhood upper respiratory tract infections was confirmed by a multicentre randomized controlled trial, conducted by van der Gaag et al. ${ }^{10}$ In their study, 118 children were divided into two groups. The study group received dietary advice, advising the consumption of green leafy vegetables, beef and whole dairy. They found that patients who received dietary advice had, on an average, 2.9 lesser episodes per month as compared to the control group.

Dietary modification has also been successful in patients with other kinds of allergy-based disorders. In a separate study, Calatayud et al. studied the effect of the Mediterranean diet in childhood asthma. ${ }^{11}$ The authors observed that in patients following this diet, there was a decrease in frequency of asthmatic attacks, as well as a decrease in the use of inhaled corticosteroids. Despite several study in closely related areas, there are no dietary studies in literature that specifically relate to chronic rhinosinusitis.

One explanation for triggering of symptoms in patients with chronic sinusitis could be the release of histamine. Several food items have been associated with high amounts of histamine. These include fermented foods, citrus and certain other fruits, nuts, certain types of fish and chicken. However, each of these food substances encompasses a wide variety of diets and have not been studied fully. Two separate studies assessed the effect of low-histamine diet on urticarial, which is essentially an allergic condition. ${ }^{12,13}$ Both these authors reported that low-histamine diets were beneficial in decreasing symptoms of urticarial and improving the quality of life.

In the current study, chocolate was identified as the most significant trigger for symptoms of rhinosinusitis. Chocolate is technically a form of fermented food, as it is derived from cocoa beans, which are fermented forms of cacao seeds. It is high in histamine and also triggers histamine release in the body. ${ }^{14}$ In addition, chocolate also contains some amount of dairy content and sugar, which are possibly, by themselves, potential triggers for exacerbation of sinusitis. The next high 
Table 2. Comparative analysis of food groups and their frequency in triggering symptoms of rhinosinusitis

\begin{tabular}{|c|c|c|c|c|}
\hline Food categories & Sinusitis aggravated & No aggravation & Chi-square value & $P$-value \\
\hline Chocolate vs. white flour & $\begin{array}{l}41 \\
34\end{array}$ & $\begin{array}{l}350 \\
331\end{array}$ & 0.3309 & 0.565 \\
\hline Chocolate vs. fried foods & $\begin{array}{l}41 \\
27\end{array}$ & $\begin{array}{l}350 \\
341\end{array}$ & 2.304 & 0.128 \\
\hline Chocolate vs. pastries & $\begin{array}{l}41 \\
24\end{array}$ & $\begin{array}{l}350 \\
363\end{array}$ & 4.66 & 0.03 \\
\hline Chocolate vs. fatty meats & $\begin{array}{l}41 \\
23\end{array}$ & $\begin{array}{l}350 \\
358\end{array}$ & 5.024 & 0.02 \\
\hline Chocolate vs. white sugar & $\begin{array}{l}41 \\
20\end{array}$ & $\begin{array}{l}350 \\
345\end{array}$ & 6.38 & 0.01 \\
\hline Chocolate vs. mashed potatoes & $\begin{array}{c}41 \\
9\end{array}$ & $\begin{array}{l}350 \\
383\end{array}$ & 21.96 & $<0.0001$ \\
\hline White flour vs. fried foods & $\begin{array}{l}34 \\
27\end{array}$ & $\begin{array}{l}331 \\
341\end{array}$ & 0.94 & 0.33 \\
\hline White flour vs. pastries & $\begin{array}{l}34 \\
24\end{array}$ & $\begin{array}{l}331 \\
363\end{array}$ & 2.56 & 0.11 \\
\hline White flour vs. fatty meats & $\begin{array}{l}34 \\
23\end{array}$ & $\begin{array}{l}331 \\
358\end{array}$ & 2.83 & 0.09 \\
\hline White flour vs. white sugar & $\begin{array}{l}34 \\
20\end{array}$ & $\begin{array}{l}331 \\
345\end{array}$ & 3.91 & 0.04 \\
\hline White flour vs. mashed potatoes & $\begin{array}{c}34 \\
9\end{array}$ & $\begin{array}{l}331 \\
383\end{array}$ & 17.38 & 0.00003 \\
\hline Fried foods vs pastries & $\begin{array}{l}27 \\
24\end{array}$ & $\begin{array}{l}341 \\
363\end{array}$ & 0.39 & 0.54 \\
\hline Fried foods vs fatty meats & $\begin{array}{l}27 \\
23\end{array}$ & $\begin{array}{l}341 \\
358\end{array}$ & 0.51 & 0.47 \\
\hline Fried foods vs white sugar & $\begin{array}{l}27 \\
20\end{array}$ & $\begin{array}{l}341 \\
345\end{array}$ & 1.04 & 0.31 \\
\hline Fried foods vs mashed potatoes & $\begin{array}{c}27 \\
9\end{array}$ & $\begin{array}{l}341 \\
383\end{array}$ & 10.69 & 0.0011 \\
\hline Pastries vs. fatty meats & $\begin{array}{l}24 \\
23\end{array}$ & $\begin{array}{l}363 \\
358\end{array}$ & 0.0091 & 0.92 \\
\hline Pastries vs. white sugar & $\begin{array}{l}24 \\
20\end{array}$ & $\begin{array}{l}363 \\
345\end{array}$ & 0.18 & 0.67 \\
\hline Pastries vs. mashed potatoes & $\begin{array}{c}24 \\
9\end{array}$ & $\begin{array}{l}363 \\
383\end{array}$ & 7.32 & 0.0068 \\
\hline Fatty meat vs. white sugar & $\begin{array}{l}23 \\
20\end{array}$ & $\begin{array}{l}358 \\
345\end{array}$ & 0.11 & 0.74 \\
\hline Fatty meats vs mashed potatoes & $\begin{array}{c}23 \\
9\end{array}$ & $\begin{array}{l}358 \\
383\end{array}$ & 6.81 & 0.009 \\
\hline White sugar vs mashed potatoes & $\begin{array}{c}20 \\
9\end{array}$ & $\begin{array}{l}345 \\
383\end{array}$ & 5.19 & 0.022 \\
\hline
\end{tabular}

trigger, white flour, has been associated with several other inflammatory conditions such as celiac disease. ${ }^{15}$ All the other food categories evaluated in this study have also been anecdotally associated with inflammation; however, we found low correlation for mashed potatoes, which was the only natural food that was being studied.

The next step to identifying known triggers is naturally to validate these triggers, followed by management solutions that involve avoidance. There is a definite need to design and implement randomized controlled trials, similar to the one designed by van der Gaag et al., ${ }^{10}$ evaluating each of the specific food categories against controls. Once evidence based triggers are identified, proper dietary advice can go a long way in reducing frequency and severity of symptoms in patients suffering from chronic rhinosinusitis.

\section{Conclusion}

In the current study, we were able to identify chocolate as one of the leading triggers of symptoms of rhinosinusitis. We also identified other forms of processed foods that could trigger inflammation and aggravate sinusitis. Based on the results of this study, we recommend that patients suffering from this condition must maintain a food diary and also record their symptoms. This can help identify triggers in individual patients and can guide management of this condition. 


\section{Source of Funding}

None.

\section{Acknowledgements}

None.

\section{References}

1. Battisti AS, Modi P, Pangia J. Sinusitis. [Updated 2020 Aug 10]. In: StatPearls [Internet]. Treasure Island (FL): StatPearls Publishing; 2020 Jan-.

2. Fokkens, WJ, Lund, VJ, Mullol, J, et al. European position paper on rhinosinusitis and nasal polyps 2012. Rhinology. 2012;50(supp 23):1-329

3. Kewalramani, A, Bollinger, ME. The impact of food allergy on asthma. J Asthma Allergy. 2010;3:65-74.

4. Pang YT, Eskici O, Wilson JA: Nasal polyposis: role of subclinical delayed food hypersensitivity. Otolaryngol Head Neck Surg 2000; 122:298-301.

5. Collins MM, Loughran S, Davidson P, Wilson JA: Nasal polyposis: prevalence of positive food and inhalant skin tests. Otolaryngol Head Neck Surg 2006:135:680-683

6. Popescu, F-D. Cross-reactivity between aeroallergens and food allergens. World J Methodol. 2015;5(2):31-50

7. Cuschieri S. The STROBE guidelines. Saudi J Anaesth. 2019;13(Suppl 1):S31-S34. doi:10.4103/sja.SJA_543_18

8. Helms S, Miller A. Natural treatment of chronic rhinosinusitis. Altern Med Rev. 2006;11(3):196-207.

9. Calatayud FM, Calatayud B, Gallego JG, González-Martín C, Alguacil LF. Effects of Mediterranean diet in patients with recurring colds and frequent complications. Allergol Immunopathol (Madr). 2017:45(5):417-424. doi:10.1016/j.aller.2016.08.006
10. van der Gaag E, Brandsema R, Nobbenhuis R, van der Palen J, Hummel T. Influence of Dietary Advice Including Green Vegetables, Beef, and Whole Dairy Products on Recurrent Upper Respiratory Tract Infections in Children: A Randomized Controlled Trial. Nutrients. 2020;12(1):272. Published 2020 Jan 20. doi:10.3390/nu12010272

11. Calatayud-Sáez FM, Calatayud Moscoso Del Prado B, Gallego FernándezPacheco JG, González-Martín C, Alguacil Merino LF. Mediterranean diet and childhood asthma. Allergol Immunopathol (Madr). 2016:44(2):99-105. doi:10.1016/j.aller.2015.04.007

12. Wagner N, Dirk D, Peveling-Oberhag A, et al. A Popular myth - lowhistamine diet improves chronic spontaneous urticaria - fact or fiction? J Eur Acad Dermatol Venereol. 2017;31(4):650-655. doi:10.1111/jdv.13966

13. Son JH, Chung BY, Kim HO, Park CW. A Histamine-Free Diet Is Helpful for Treatment of Adult Patients with Chronic Spontaneous Urticaria. Ann Dermatol. 2018;30(2):164-172. doi:10.5021/ad.2018.30.2.164

14. San Mauro Martin I, Brachero S, Garicano Vilar E. Histamine intolerance and dietary management: A complete review. Allergol Immunopathol (Madr). 2016:44(5):475-483. doi:10.1016/j.aller.2016.04.015

15. Fardet A. Wheat-based foods and non celiac gluten/wheat sensitivity: Is drastic processing the main key issue?. Med Hypotheses. 2015;85(6): 934-939. doi:10.1016/j.mehy.2015.09.007

This work is licensed under a Creative Commons Attribution-NonCommercial 3.0 Unported License which allows users to read, copy, distribute and make derivative works for non-commercial purposes from the material, as long as the author of the original work is cited properly. 